\title{
Study on Spatial and Temporal Variability of Rural Household Energy Consumption in Plateau Mountain Areas of Southwest China
}

\author{
Li Xinxin ${ }^{1,2}$, Shi Zuliang ${ }^{1}$ \\ ${ }^{1}$ Rural Energy and Environment Agency, Ministry of Agriculture and Rural Affairs, Beijing, China \\ ${ }^{2}$ College of Resources and Environmental Sciences, China Agricultural University, Beijing, China
}

\section{Email address:}

lixinxinwork@163.com (Li Xinxin),shizuliang1985@163.com (Shi Zuliang)

\section{To cite this article:}

Li Xinxin, Shi Zuliang. Study on Spatial and Temporal Variability of Rural Household Energy Consumption in Plateau Mountain Areas of Southwest China. International Journal of Energy and Environmental Science. Vol. 4, No. 5, 2019, pp. 61-66. doi: $10.11648 /$ j.ijees.20190405.11

Received: October 15, 2019; Accepted: November 7, 2019; Published: November 14, 2019

\begin{abstract}
Rural energy consumption of China is only about $20 \%$ to total energy consumption, but the consumer number has accounted for $70 \%$ of the population. Rural household energy is closely related to life quality of farmers and regional ecological environment, which concerns building a new socialist countryside, and occupies an important position in the national energy consumption system. Nowadays, the quantity and quality of rural life energy has been greatly improved, but environment pollution caused by burning of residue straw and extensive use of non-renewable fossil fuels is spread. Guiding the rural life energy consumption to a efficient, clean, environment-friendly direction is urgent. Southwest Plateau Mountain is one of the traditional geographical divisions in China, with abundant biomass resources and distinctive regional characteristics. However, few studies has been conducted to research the change of the rural life energy consumption structure in the region. Therefore, the spatial and temporal variation of rural life energy consumption was analyzed through the rural energy data from 1992 to 2017. The results showed that total consumption and per capita consumption of energy in rural life presented a step change characteristic of increasing firstly and then decreasing from 1992 to 2017 (the highest was in 2008). Total consumption and per capita consumption of rural life energy in 2017 increased by 3.64\% and $65.13 \%$ respectively compared to 1992 . Coal, straw, firewood are the main types of rural energy consumption in this area, gas, oil, liquefied petroleum gas, natural gas, coal gas and solar energy consumption ratio have improved to varying degrees with the evolution of the year. The proportion of commercial energy consumption increased from $30.05 \%$ in 1992 to $57.60 \%$ in 2017 , reflecting the energy structure transforming from the traditional patterns to the diversification, utility and commercialization utilization pattern. The regional distribution of energy consumption intensity basically showed the characteristics of north high and south low, energy consumption structure, demonstrating significant regional differences. The largest energy consumption energy in Sichuan was firewood, and it was coal in Yunnan, Chongqing and Guizhou, and electricity in Tibet. Taking the complementary energy consumption mode of commercial energy and non-energy commercial energy according to local conditions, promoting the efficient and clean use of straw, firewood and solar energy will be the inevitable choice for sustainable development of rural energy in mountain plateau areas in Southwest China.
\end{abstract}

Keywords: Plateau Mountain Areas of Southwest China, Rural Household Energy, Consumption Structure, Regional Characteristics

\section{Introduction}

Energy is the driving power in the modern economic society. Rural energy is related to the supply and consumption in rural areas, involving in all aspects of agricultural production and rural living environment. With the rapid development of economic society, rural energy is becoming more and more prominent in China's energy industry. Sustainable consumption of rural energy is the key element mattering rural economy development and famers' living 
standard, and also the primary task to guarantee the national energy security and put forward energy conservation $[1,2]$. With a huge amount of rural population and conventional biomass energy such as straw, core wood and the forth, indoor pollution and ecology environment damage is getting more and more severe [3-5]. Under the overall urbanization background, profound changes has happened to the population number, living style and consumption notion in rural areas, which make tremendous impacts on the amount and structure of energy consumption [6-8]. Therefore, analyzing the intensity, structure and evolution characteristic of rural household energy consumption has important meanings for rural areas to adapt the new develop needs and realize the sustainable development.

China is a large country, with huge diversities in energy resources, economy situation, society, culture and geography nature, as well as distinctive spatial and temporal variability of rural household energy consumption [9]. Taking typical regions as the classified researching sample is a scientific and important way to demonstrate the current situation and predicate the future demands of rural energy consumption. Part of the Chinese land, such as Beijing-Tianjin-Hebei region and eastern China has been analyzed and predicted in rural energy consumption by early studies [10-13], but other areas in China have not been studied yet. Plateau mountain areas of Southwest China cover Yunnan, Guizhou, Sichuan, Chongqing and Tibet five provinces, with complex terrain and climate features, are in great demands of household energy in winter season, which could well explain the important theoretical and practical value of rural energy consumption structure research.

\section{Data Resources}

Data in this paper mainly based on National Rural Renewable Energy Statistics published by Ministry of Agriculture and Rural Affairs, containing the total consumption number of coal, electronic power, oil, liquefied petroleum gas, natural gas, coal gas, straw, core wood, biogas and solar energy in plateau mountain areas of Southwest China from year 1992 to 2017. Rural population numbers in different time or from administrative regions are calculated by published data derived from National Statistical Yearbook.

\section{Results and Discussion}

\subsection{Variation Tendency of Rural Energy Consumption Intensity}

The total and per capita energy consumption in plateau mountain areas of Southwest China correlates well during our research, demonstrating a falling tendency after the first increase. The total energy consumption has increased from 5.324 billion tons in 1992 to 11.625 billion tons in 2008, with increment rate of $7.40 \%$ per year. Energy consumption per capita has increased from 0.34 ton in 1992 to 0.70 ton standard coral, with increment rate of $6.75 \%$ per year. Since 2008 , total and per capita energy consumption had begun to decline. The total energy consumption has decreased from 11.625 billion tons standard coral in 2008 to 5.5176 billion tons standard coral in 2017, with a decrement rate of $5.84 \%$ per year. Energy consumption per capita has decreased from 0.83 ton standard coral in 2008 to 0.56 ton standard coral in 2017, with decrement rate of $3.70 \%$. The first-increase-then-decline tendency differs from earlier research showing a persistent increase [14-15], which could be related to the factors of energy structure adjustment, increment in energy efficiency, and change in rural population [16]. Compared with the whole national situation, plateau mountain areas' energy consumption is in disadvantage. In year of 2008, rural household energy consumption over China is 1.38 ton, which is considerably higher than the plateau mountain areas ( 0.83 ton), probably because of the economic development status and energy availability [14].

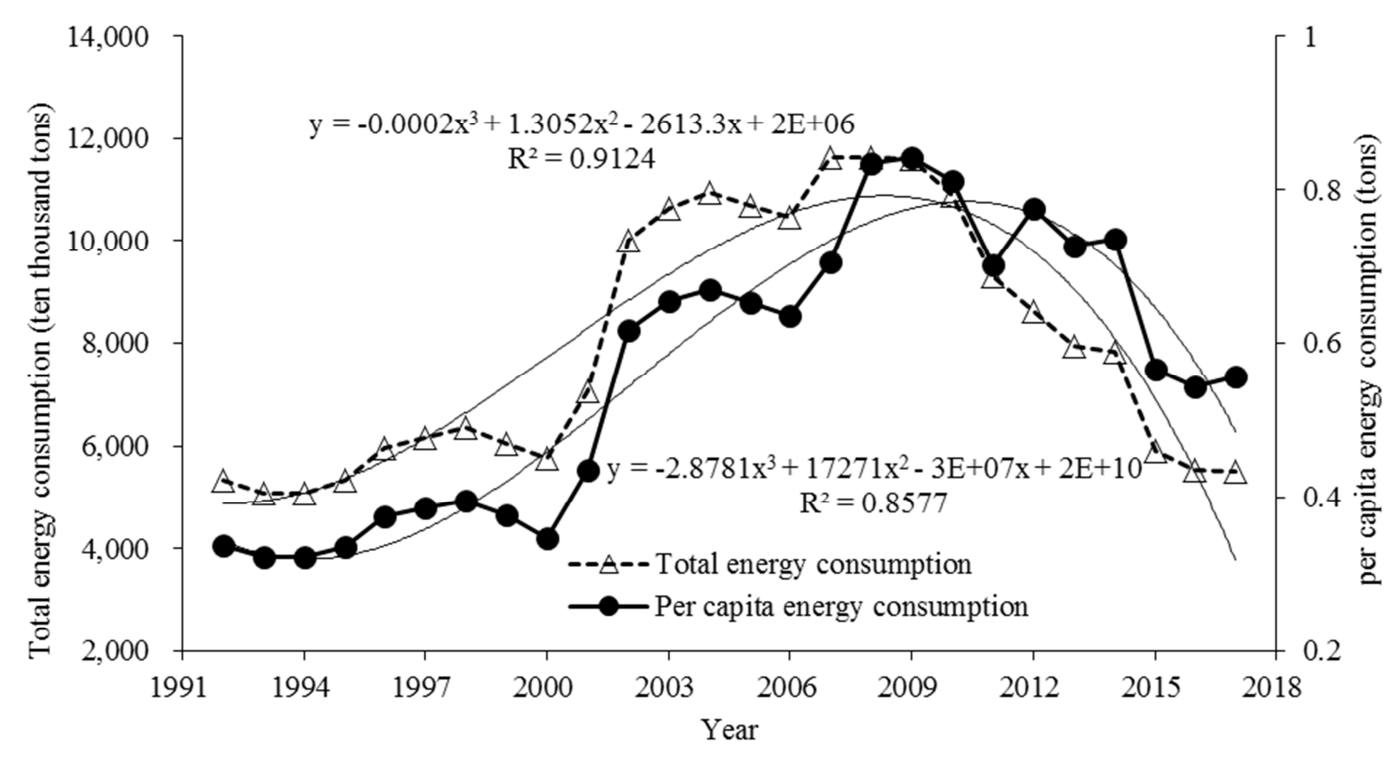

Figure 1. Total and per captia mean rural household enery consumption in plateau mountain areas of Southwest China. 


\subsection{Variation Tendency of Rural Energy Consumption Structure}

As shown in figure 2, rural energy consumption structure in plateau mountain areas of Southwest China changed greatly in recent years. In 1992, the main energy used by the area is core wood, coal and straw, rating 46\%, 27.65\%, 23.3\% separately. Electricity, biogas and oil have a lower share in rural energy consumption, rating $2.11 \%, 0.65 \%, 0.38 \%$. In 2017 , the main energy type is coal and core wood, rating $36.61 \%, 27.18 \%$ separately. Electricity, biogas, oil and solar energy consumption share have increased by different degrees, rating $7.99 \%, 5.40 \%, 4.47 \%, 2.20 \%, 6.66 \%, 1.86 \%$, while straw consumption rate decreased to $7.62 \%$.

Core wood is a vital kind of biomass energy and have been widely used as rural energy, especially in plateau mountain areas of southwest China due to their abundant forest resources and high vegetation coverage. But with the strict water and soil conservation policies and energy replacement [17], core wood consumption rate have gradually declined, from $46 \%$ in 1992 to $27.18 \%$ in 2017 . As the by-product of agricultural industry, straw has a long history being used as rural household energy, and was the most important energy resource in plateau mountain areas of Southwest China. But with the popularization of fuel and coal saving stove [18], as well as the application of different clean energy, the consumption of straw as rural energy has declined greatly, form $23.3 \%$ in 1992 to $7.62 \%$ in 2017 . The consumption ratio of coal has increased form $27.56 \%$ in 1992 to $36.61 \%$ in 2017 , making it the prominent energy type, probably because the rich abundance of coal in Guizhou province [19]. Along with the rapid development of rural economy, rural family consumed more electric cooker, induction cooker, air conditioner, refrigerator, washing machine and television, making electricity consumption rate increased from $2.11 \%$ in 1992 to $7.99 \%$ in 2017 . Recently, our country has increased the input to biogas development, especially in Yunnan, Sichuan and Guizhou provinces [20], making the biogas consumption rate increase from $0.65 \%$ to $5.40 \%$. Solar energy has gradually been popularized in Tibet and Yunan province since 2006 [21], with a consumption rate of $2.2 \%$ in 2017 , increased by $1.58 \%$.

With the economy development and energy guarantee system's building, the energy supply in plateau mountain areas of southwest China has enriched a lot. Oil, liquefied petroleum gas, natural gas and coal gas gradually stepped into thousands of rural households. Oil is mainly used as vehicle energy resource while liquefied petroleum gas, natural gas and coal gas are mostly used as cooking energy.

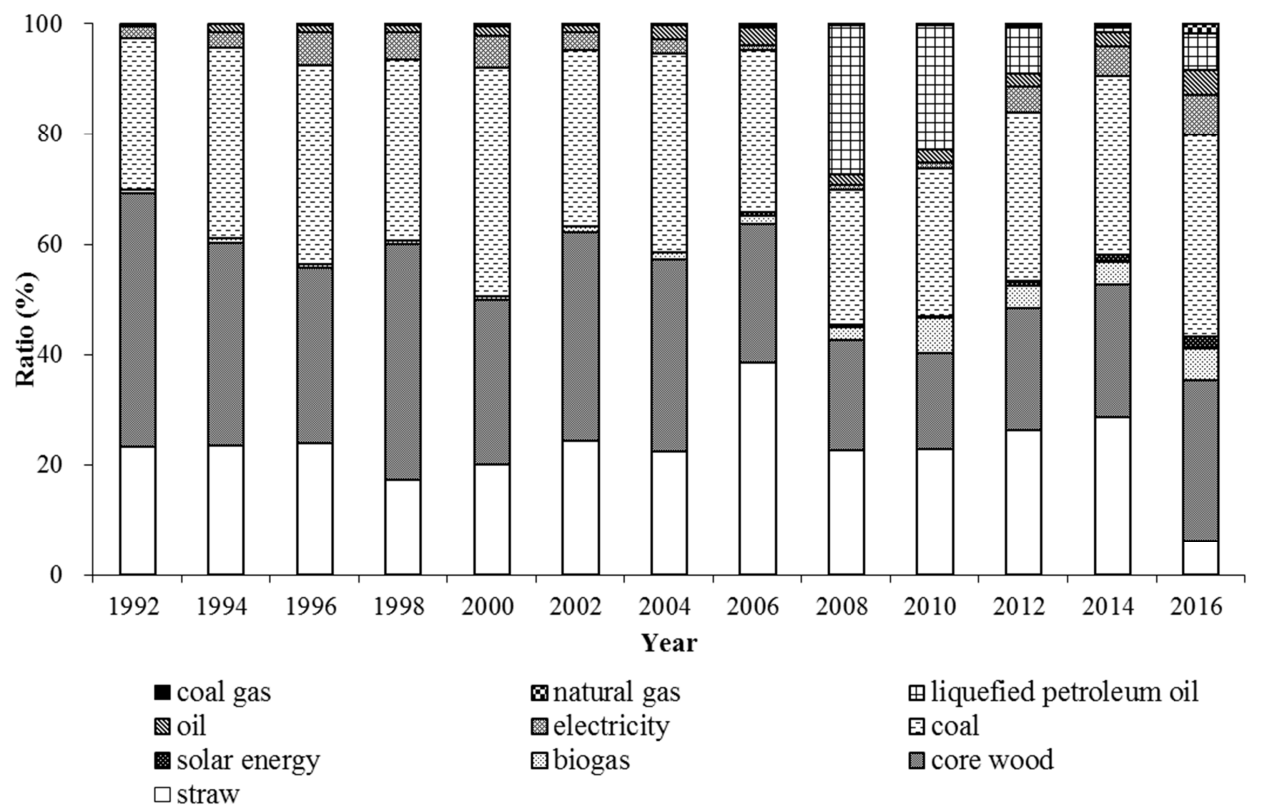

Figure 2. Variance of rural household enery consumption structure in plateau mountain areas of Southwest China

\subsection{Comparison and Analyzation of Commodity and Non-Commodity Rural Household Energy Consumption}

Commodity energy is related to coal, electricity, oil, natural gas, liquefied petroleum gas and coal gas, while non-commodity energy is related to core wood, straw, biogas, solar energy. As demonstrated in figure 3, rural household commodity energy consumption shows an uprising trend followed by a declining trend, from 1.6 billion tons in 1992 to
6.357 billion tons of 2007 , then down to 3.178 tons in 2017 , which is still higher than 1990 s by $98.65 \%$. Non-commodity energy consumption correlates well with commodity energy consumption, which increased to 6.9052 ton in 2006 from 3.7242 ton in 1992, then was down to 2.3997 ton in 2017, lower than early 1990 s by $37.18 \%$. Commodity energy consumption per capita and non-commodity energy consumption per capita are generally in accordance with the total amount, increasing to 0.32 ton in 2017 from 0.1 ton in 
1992. Non -commodity energy per capita in 1992 and 2017 are both 0.24 ton. In the early $1990 \mathrm{~s}, 69.95 \%$ of the energy consumption in plateau mountain areas of Southwest China is non-commodity energy, while $30.05 \%$ of it is commodity energy. In 2017, the non-commodity energy consumption rate decreased to $42.40 \%$, while commodity energy consumption rate increased to $57.60 \%$, showing the using pattern transferring from conventional style to commercial one, indicating the rocketing rural living standard for more than 20 years and the austere challenge brought by various commodity energy demand and distinctive consumption structure [16].

\subsection{Spatial Variability of Rural Household Energy Consumption}

Research data in this paper mainly covers Tibet, Sichuan, Chongqing, Guizhou and Yunnan province, but lack part of the data in Tibet and Chonqing province. Taking the land area and population difference into concern, our study focused on per capita consumption level to make the comparisons accessible. Plateau mountain areas in southwest China have significant variation in spatial feature. Taking 2017 for example, rural household energy consumption per capita in Sichuan, Chongqing, Yunnan and Guizhou is 0.55 ton standard coal, 0.48 ton standard coal, 0.46 ton standard coal, 0.78 ton standard coal separately, which is higher than the other provinces due to the considerately high coal consumption per capita. Tibet rural household energy consumption per capita is 0.21 ton standard coal, much lower than the rest four provinces and differing from the research of Li Weihu [21]. The main influencing factors of the low exchange rate and high cost energy consumption in Tibet are the special location, lack of the biomass and coal resources, as well as the low economy and outdated energy facilities [22]. In general, the rural energy consumption in plateau mountain areas of Southwest China is lower in the south and higher in the north, which is in accordance with the distribution characteristics all over China [14].

Spatial difference in rural household consumption also can be reflected in the consumption structure of different provinces or cities. Sichuan as one of the three main food producing provinces, is abundant in straw resources but only has a per capita energy consumption of 0.043 ton standard coal in 2017 , rating $7.81 \%$ of household energy consumption. In the same year, the straw resources collectable is 3.339 tons, and the utilization rate is $87 \%$, over $50 \%$ of which is returned to the field as fertilizer [23]. There is still great potential in energy utilization to enhance straw energy utilization rate and level, especially in clean stove, biomass pellet fuel, and variable stalks of methane utilization. Coal energy consumption per capita in Guizhou is 0.442 ton standard coal, accounting for $56.44 \%$ of energy consumption per capita. Guizhou is the richest province in coal resource in southern China and is known as the coal ocean in southwest China [19], which could explain the high consumption rate per capita. In Chongqing, coal energy and natural gas consumption per capita is 0.172 ton standard coal, accounting for $35.92 \%$ of energy consumption per capita, mainly because Chongqing has the most abundant mineral resources among big and middle cities all over China, which has a $27 \%$ share in natural gas reserves [24]. But according to Fanli's study [25], coal originating from Chongqing is no better than average, and has limit developing space with high sulfur and ash content. Yunnan as one of the four forest area, has rich forest resources, the core wood energy consumption per capita of which accounts for $24.05 \%$ of energy consumption per capita. Tibet locates in Qingzang plateau and has quite accessible and abundant solar energy potential, so the rural household energy type is mainly about solar energy, electricity and liquefied petroleum gas. The three type energy summons to 0.183 ton standard coal, rating $89.31 \%$ of rural energy consumption per capita in total. The above results show that, resources accessibility and economic level are the two main factors effecting energy consumption.

By making comparisions of the five provinces' rural household energy consumption per capita in different time, we could find that energy consumption per capita increased remarkably in all the five provinces, though Sichuan demonstrated a corresponding increment between commodity and non-commodity energy consumption, while Chongqing, Guizhou, Yunnan and Tibet showed a sharp enhancement in commodity energy consumption along with a decrement in non-commodity energy consumption.

Table 1. Rural household enery consumption structure for five provinces in plateau mountain areas of Southwest China.

\begin{tabular}{|c|c|c|c|c|c|c|c|c|c|c|}
\hline \multirow{2}{*}{ Energy structure } & \multicolumn{2}{|c|}{ Chongqing } & \multicolumn{2}{|c|}{ Sichuan } & \multicolumn{2}{|c|}{ Guizhou } & \multicolumn{2}{|c|}{ Yunnan } & \multicolumn{2}{|l|}{ Tibet } \\
\hline & 1997 & 2017 & 1992 & 2017 & 1992 & 2017 & 1992 & 2017 & 2006 & 2017 \\
\hline Straw & 0.1431 & 0.0885 & 0.1001 & 0.0428 & 0.0428 & 0.0203 & 0.0533 & 0.0424 & 0.0453 & 0 \\
\hline Core wood & 0.1394 & 0.0889 & 0.0892 & 0.1808 & 0.2283 & 0.1957 & 0.2875 & 0.1113 & 0.0491 & 0 \\
\hline Biogas & 0.0021 & 0.0239 & 0.0033 & 0.0343 & 0.0001 & 0.0168 & 0.0010 & 0.0373 & 0 & 0.0145 \\
\hline Solar energy & 0 & 0.0075 & 0 & 0.0064 & 0 & 0.0055 & 0 & 0.0228 & 0 & 0.0773 \\
\hline Non-commodity energy & 0.2847 & 0.2089 & 0.1926 & 0.2642 & 0.2712 & 0.2384 & 0.3417 & 0.2139 & 0.0944 & 0.0918 \\
\hline Coal & 0.1249 & 0.1334 & 0.0648 & 0.1546 & 0.2285 & 0.4423 & 0.0584 & 0.1510 & 0 & 0 \\
\hline Electricity & 0.0102 & 0.0501 & 0.0082 & 0.0332 & 0.0038 & 0.0562 & 0.0074 & 0.0503 & 0 & 0.0553 \\
\hline Oil & 0.0072 & 0.0358 & 0.0006 & 0.0241 & 0.0023 & 0.0294 & 0.0025 & 0.0195 & 0 & 0.0076 \\
\hline Liquefied petroleum gas & 0.0001 & 0.0118 & 0 & 0.0583 & 0 & 0.0168 & 0 & 0.0281 & 0 & 0.0522 \\
\hline Natural gas & 0.0010 & 0.0386 & 0 & 0.0142 & 0 & 0.0007 & 0 & 0.0001 & 0 & 0 \\
\hline Coal gas & 0 & 0.0002 & 0 & 0 & 0 & 0 & 0 & 0 & 0 & 0 \\
\hline Commodity energy & 0.1434 & 0.2699 & 0.0735 & 0.2844 & 0.2345 & 0.5453 & 0.0682 & 0.2490 & 0 & 0.1151 \\
\hline Total & 0.4281 & 0.4788 & 0.2662 & 0.5487 & 0.5058 & 0.7837 & 0.4100 & 0.4630 & 0.0944 & 0.2069 \\
\hline
\end{tabular}




\section{Conclusion and Advice}

As with the economy development, the total energy consumption and per capita energy consumption both showed a increasing tendency followed by a declining tendency, reaching a peak in year of 2008. Rural energy consumption structure demonstrated a visible transfer from conventional utilization pattern to diversification, premiumization and commercialization mode. Coal, electricity, oil, biomass gas rate increased to $36.61 \%, 7.99 \%, 4.47 \%, 5.40 \%$ in 2017 to $27.56 \%$, $2.11 \%, 0.38 \%, 0.65 \%$ separately. Solar energy, liquefied petroleum gas, natural gas and coal gas has made a breakthrough, increasing to $2.20 \%, 6.66 \%, 1.86 \%, 0.01 \%$. Straw and core wood declined to $7.62 \%$ and $27.18 \%$ from $23.30 \%$ and $46.00 \%$ in 1992 , with the commodity energy rate increasing to $57.60 \%$ from $30.05 \%$. Rural energy consumption quantity basically shows a characteristics of north high and south low, with a remarkable spatial differences. Rural energy consumption categories in Sichuan, Guizhou and Yunnan are mainly includes core wood and coal, with Chongqing majors in coal, straw and core wood, and Tibet majors in electricity and liquefied petroleum oil. Resources accessibility and economy situation are the main factors influencing rural energy consumption. Therefore, plateau mountain areas should combine factors like resource nature, economy level, ecology status to adapt suitable developing way in order to push forward the efficient supply of rural energy consumption. Considering the relatively high sulfur and ash content in Chongqing's coal, government of Chongqing should primarily develop commodity energy such as natural gas. Sichuan is abundant in straw, water, and natural gas resources, but has a less reservation in coal and oil. So it should primarily develop clean energy such as natural gas, biogas, straw gasification, hydropower and electric power, meanwhile make comprehensive utilization of biogas slurry, biogas residue and marsh gas. With the sustainable development consideration and a high reservation in core wood and coal reserves, Guizhou should pay attention to fostering firewood forest, as well as promoting the application of clean stove. Since Yunnan has a unique vertical tree-dimension climate and plants resources, it should carry out energy crop cultivation widely, develop agricultural biological energy and recycle economy, as well as accelerate the low-carbon rural construction and biogas application. Tibet is one of the most ample areas concerning solar energy, and is still with a high ration of hydroelectric power. Thinking from the grassland and forest conservation, Tibet government should primarily develop solar water heater utilization and solar cooker, in order to form the utilization pattern that can complement each other.

\section{References}

[1] Shimei $\mathrm{Wu}$, Xinye Zheng, Chaoying You, et al. Household energy consumption in rural China: Historical development, present pattern and policy implication [J]. Journal of Cleaner Production, 2019, 211: 981-991.
[2] Byrne J, Zhou A M, Shen B. Analyzing the dynamic impact of electricity futures on revenue and risk of renewable energy in China [J]. Energy Policy, 2019, 132: 678-690.

[3] Wang X H, Feng Z M, Gao X F, et al. Assessment of bioenergy development potential and its environmental impact for rural household energy consumption: A case study in Shandong, China [J]. Renewable and Sustainable Energy Reviews, 2017, 67: 1153-1161.

[4] Sheng J. The crops traw opening buring control research based on the government-farmer-enterprise cooperation game $[\mathrm{J}]$. Chinese Journal of Agricultural Resources and Regional Planning, 2015, 36 (4): 48-53.

[5] Qiang Wang, Mei-Po Kwan, Kan Zhou, et al. Impacts of residential energy consumption on the health burden of household air pollution: Evidence from 135 countries [J]. Energy Policy, 2019, 128: 284-295.

[6] Li B. Hierarchical structure analysis of urban carbon metabolism: A case study of Beijing, China [J]. Ecological Indicators, 2019, Article 105602.

[7] Zhao C S, Niu S W, Zhang X. Effects of household energy consumption on environment and its influence factors in rural and urban areas [J]. Energy Procedia, 2012, 14: 805-811.

[8] Yu Chen, Wei Hu, Paul Chen, et al. Household biogas CDM project development in rural China $[\mathrm{J}]$. Renewable and Sustainable Energy Reviews, 2017; 67: 184-191.

[9] Li G Q, Nie H L, Yang Y L. Regional Disparities and Influencing Factors of Rural Energy Consumption in China [J]. Journal of Shanxi Finance and Economics University, 2010, 32 (2):68-73.

[10] Zhang Y J, Jiang J Y, Ye J D et al., Rural energy consumption analysis and the policy advice of coal reduction and replacement in Beijing-Tianjin-Hebei.[J]. Energy of China, 2014, 36 (7): 26-28.

[11] Han Y, Wang D L, Bi Y Y. Analysis on attribute structure of rural household energy consumption in tancheng country [J]. Chinese Journal of Agricultural Resources and Regional Planning, 2013, 34 (4): 141-144.

[12] Wang X H. Study on rural household energy consumption in [J]. Chinese Agricultural Science Bulletin, 2012, 28 (26): 196-200.

[13] Zhu J C, Li R H, Zhang Z Z et al., The rural household energy consumption structure analysis of Shanxi province [J]. Renewable Energy Resources, 2012, 30 (2): 125-130.

[14] Zhang L X, Hu Q H, Wang C B. Spatiotemporal distribution characteristics and policy evolution of rural energy consumption in China [J]. Transactions of CSAE, 2011, 27 (1): $1-9$.

[15] Rao M N, Reddy B S. Variations in energy use by Indian households: an analysis of micro level data [J]. Energy Policy, 2007, 32 (2): 143-153.

[16] Qiu H G, Yan J B, Li D W, Han W. Residential energy consumption in rural China:current situation and determinants for future trend- an empirical study based on field survey data of 4 provinces [J]. China Soft Science, 2015, 11: 28-38. 
[17] Zhang X Q, Zhan K Q. rural energy construction in soil and water conservation in karst mountains of guizhou [J]. Soil and Water Conservation in China, 2011 (11): 19-21.

[18] Wei W, Zhang X K, Zhu S S et al., The overview and prospect in biomass energy exploitation and utilization in China [J]. Journal of Agricultural Mechanization Research 2013 (3): $7-11$.

[19] Ziqi Zhao, Shu Tao, Dazhen Tang, et al. A mathematical method to identify and forecast coal texture of multiple and thin coal seams by using logging data in the Panguan syncline, western Guizhou, China [J]. Journal of Petroleum Science and Engineering, 2019, in press.

[20] Science, Technonlgy, and Education Department of MOARA, Rural Energy and Environmental Agency, MOARA. Rural Statistics in China (2009-2013) [M]. China Agricultural Press, 2014.

[21] Rural Energy and Environmental Agency, MOARA. 2013 Report on environmental protection of agricultural resources and rural energy development [M]. China Agricultural Press, 2014.
[22] Yuli Zhu, Ji Liang, Qing Yang, et al. Water use of a biomass direct-combustion power generation system in China: A combination of life cycle assessment and water footprint analysis [J]. Renewable and Sustainable Energy Reviews, 2019, 11.

[23] Rural Energy and Environmental Agency, MOARA. Evaluation of straw comprehensive utilization [R]. 2015

[24] Xinhua Ma. Natural gas and energy revolution: A case study of Sichuan-Chongqing gas province. [J]. Natural Indusry B, 2017, 4 (2): 91-99.

[25] Fan L, Liu D S, Chen W Z. A study of sustainable consumption of rural household energy in Chongqing [J]. Journal of southwest agricultural university (Natural Science), 2005, 27 (4): 494-499. 